\title{
BMJ Open Development of a patient-reported outcome measure for neck pain in military aircrew: qualitative interviews to inform design and content
}

\author{
Anna Dowling, ${ }^{1,2}$ Ellen Slungaard (i) , ${ }^{3,4}$ Nicola R Heneghan (1) ${ }^{2}$
}

To cite: Dowling A, Slungaard E, Heneghan NR. Development of a patient-reported outcome measure for neck pain in military aircrew: qualitative interviews to inform design and content. BMJ Open 2021;11:e039488. doi:10.1136/ bmjopen-2020-039488

- Prepublication history and additional material for this paper is available online. To view these files, please visit the journal online (http://dx.doi.org/10. 1136/bmjopen-2020-039488)

Received 16 April 2020 Revised 19 January 2021 Accepted 30 January 2021

D Check for updates

(C) Author(s) (or their employer(s)) 2021. Re-use permitted under CC BY-NC. No commercial re-use. See rights and permissions. Published by BMJ.

${ }^{1}$ Primary Care Rehabilitation Facility, Royal Air Force Marham Kings Lynn, UK

${ }^{2}$ Centre of Precision

Rehabilitation for Spinal Pain (CPR Spine), School of Sport, Exercise and Rehabilitation

Sciences, University of

Birmingham,Edgbaston,

Birmingham, UK

${ }^{3}$ Centre for Spines and Upper Quadrant Rehabilitation,

Defence Medical Rehabilitation Centre Stanford Hall, Stanford on Soar, Loughborough, UK

${ }^{4}$ School of Health Sciences, Institute of Population Health, University of Liverpool, Liverpool, UK

Correspondence to

Dr Nicola R Heneghan;

n.heneghan@bham.ac.uk

\section{ABSTRACT}

Introduction The prevalence of flight-related neck pain is $70 \%$ in UK fast jet pilots; much higher than the general population. The Aircrew Conditioning Programme and direct access physiotherapy exist to minimise the impact on military capability, but a population specific patient-reported outcome measure (PROM) is required to investigate the effectiveness of these. We aimed to explore the experiences of flight-related neck pain to inform the content validity and development of a population specific PROM.

Methods Qualitative semistructured interviews combining phenomenological and grounded theory methods, reported using Consolidated criteria for Reporting Qualitative research guidelines. A purposive sample of 10 fast jet pilots with neck pain was recruited. Concept elicitation interviews were audio recorded, transcribed verbatim along with field notes. Data analysis involved subject and methodological expertise used a concept elicitation approach.

Results Participants included 10 male fast jet pilots, age 34.7 years. Identified themes included: (1) physical symptoms associated with flying activities; (2) occupational effects revealed modifications of flying, or 'suboptimal' performance owing to neck pain; (3) psychological effects revealed feelings or worry and (4) social and activity effects showed impact on out of work time.

Conclusion Population-specific occupational, psychological and social factors should be considered alongside physical symptoms when managing neck pain in military aircrew. Findings support the development of a PROM specifically designed for military aircrew with neck pain.

\section{INTRODUCTION}

Flight-related neck pain is a common musculoskeletal problem for military pilots, with prevalence reported as $66 \%$ for all Royal Air Force (RAF) aircrew, and $70 \%$ for UK fast jet pilots. ${ }^{1}$ One-year estimates for Danish helicopter pilots were $43 \%-48 \%$, relative to $26 \%$ in the general population. ${ }^{2}$ Neck pain incidence is consistently higher relative to the general population despite several neck
Strengths and limitations of this study

- Findings provide fast jet pilots' perspective on the implications of neck pain to inform content validity of a population-specific patient-reported outcome measure.

- The study design and methods are informed and reported in line with published guidance (Consolidated criteria for Reporting Qualitative research, concept elicitation).

- The sample included only male participants from one military squadron.

- Further research is required to enable cognitive debriefing of the derived domains.

pain risk factors, such as age, physical inactivity and female gender, being lower among military groups. ${ }^{3}$

UK Defence Rehabilitation services have taken steps to address this issue and mitigate known under reporting of neck pain among aircrew. ${ }^{4}$ The Aircrew Conditioning Programme (ACP), ${ }^{5}$ which includes exercises which target the neck, has been introduced due to evidence supporting targeted strength training as a preventative strategy, ${ }^{4}{ }^{6}$ and direct access to physiotherapy services are now available to aircrew. However, in the absence of a population-specific outcome measure the effectiveness of these interventions remains unclear and is identified as a UK Defence Rehabilitation research priority. ${ }^{7}$

Patient-reported outcome measures (PROM) facilitate healthcare service quality improvement, and are integral to evidencebased practice. PROM can be disease specific (eg, Neck Disability Index (NDI) ) or generic (eg, Numerical Pain Rating Scale), where disease-specific measures are more sensitive to change in a single patient with regional specific musculoskeletal dysfunction. ${ }^{8}$ This supports their use for investigating the effectiveness of interventions such as conditioning 
programmes. ${ }^{9}$ The NDI is the most widely used and validated disease-specific neck PROM, ${ }^{10}$ although its applicability to military aircrew, with unique psychological and physical occupational requirements is unknown. This refers to the content validity of a psychometric measure, and considers the relevance of a PROM to the population of interest. The COnsensus-based Standards for the selection of health Measurement Instruments (COSMIN) checklist, a well-established PROM quality assessment tool, requires that 'age, gender, disease characteristics, country and setting' are well matched. ${ }^{11}$ In addition to demographic and disease-related differences, the occupational and ergonomic demands vary greatly between the general and military populations. ${ }^{12}$ Poor head postures, continuous vibration, repetitive movements, sustained static postures and neck loading from combat flying equipment are all unique military risk factors. ${ }^{12}$ Beyond the physical factors, psychological factors such as working on military operations creates a further set of population-specific risk factors. ${ }^{13} 14$ Military culture may influence healthcare attitudes and beliefs, with evidence indicating that pilots were reluctant to provide accurate information ${ }^{15}$ and seek treatment for neck pain. ${ }^{4}$ These factors may alter the psychometric properties of PROM by affecting how individuals approach tasks and score questionnaire items. ${ }^{16}$ It is evident that the COSMIN content validity requirements would not be met by an existing PROM and is needed to evaluate effectiveness of the ACP or changes in aircrew neck complaints over time.

Across the military aircrew populations, neck pain in fast jet pilots poses a greater flight safety risk to due to higher pain prevalence, ${ }^{1}$ and pilots flying solo. Training and airframe costs are also relatively higher, which increases the price of pilot hours lost to neck pain. ${ }^{17}$ This qualitative study, therefore, aimed to explore the psychological, social and occupation factors of flight related neck pain in fast jet aircrew during their career to inform the design and content validity of a new populationspecific PROM.

\section{Theoretical framework}

The study followed the concept elicitation format for a new PROM; the methodological orientation combined phenomenological and grounded theory approaches, adapted to consider prior knowledge to inform the study design and topic guide. ${ }^{6}$ This included review of existing literature which has critiqued the content validity of the NDI and developed a population-specific tool for whiplash associated disorders (WAD) ${ }^{18}{ }^{19}$ (grounded theory) and exploring fast jet pilot participants' own experiences and perceptions of neck pain (phenomenology). In line with the study aims, this allowed us to acquire an in depth understanding of the experiences of neck pain from individual fast jet pilots. The study was reported using the Consolidated Criteria for Reporting Qualitative Studies (online supplemental file 1). ${ }^{20}$

\section{Design and setting}

Qualitative semistructured interviews of the experiences of neck pain in fast jet pilots (Typhoon flying squadron) were conducted at RAF Akrotiri, Cyprus between 17 July 2018 and 25 July 2018.

\section{Interviews}

Semistructured interviews were used to maximise the insight of neck pain in fast jet pilots across the biopsychosocial framework. This allowed us to explore in depth past and current experiences of neck pain, attitudes and beliefs about neck pain, associated occupational factors and impact on function and performance within and outside work.

\section{Interview procedure and topic guide}

Semistructured interviews were conducted by a musculoskeletal physiotherapist $(\mathrm{AD})$ with 10 years musculoskeletal physiotherapy experience, and 7 years working with RAF fast jet pilots. Participants were unknown to the researcher and no prior relationship was established. Interviews lasted between 15 and $50 \mathrm{~min}$ and were recorded using a digital voice recorder. Participants were encouraged to talk for as long as was needed. No one else was present.

The topic guide (box 1) was developed by the research team (AD, ES and NRH) in accordance with published guidance $^{6}(1)$ a disease model for neck pain in the general population, ${ }^{21}$ modified to acknowledge population specific differences (2) a proposed endpoint model for a new PROM for military aircrew (figure 1), and the hypothesised conceptual framework (figure 2A). The derived topic guide incorporated existing evidence and review of items in existing PROM. This included previous work, which critiqued the content validity of the NDI, and informed the development of a population specific tool for WAD. ${ }^{1819}$ (online supplemental file 2) The topic guide was piloted with fast jet pilots without a history of neck pain in advance of the main data collection to assess the feasibility, including clarity of questions and timing of the interview.

\section{Participants}

Sampling and recruitment

Purposive sampling ${ }^{22}$ was used to recruit fast jet aircrew across a range of characteristics, including age, gender, flying experience, fast jet flying hours and neck pain presentations. The sample size was predetermined at ten participants, as this was deemed sufficient to reach concept saturation. ${ }^{6}{ }^{23}$ Inclusion criteria were: member of Typhoon flying squadron, qualified fast jet pilot, fully operational flight status at enrolment or lost operational flight status due to flying related neck pain (no other reason). Exclusion criteria included: no previous occurrences of flight-related neck pain. A participant information sheet was distributed by email to potentially eligible pilots; all those approached agreed to participate in the study. 
Box 1 Topic guide was developed by the research team and piloted in advance of the main data collection

\section{Starting instructions:}

- Thanks so much for agreeing to take part in this research. Introductions.

- As you may have seen on the participant information sheet, the reason for this research is to try and collect information that will help create a neck pain questionnaire that is relevant to the specific needs of military aircrew. These questionnaires are useful to help us evaluate the physiotherapy services that are currently being provided to military aircrew, with the aim of hopefully building and improving and on them.

- You are free to stop the interview and withdraw your consent to participate in this research at any point, if you decide this during the interview then please let me know. This will in no way affect your onward service career. Also, if you decide after the interview that you don't want your information to be used in the research this is also fine, as long as you notify me within a week of completion of this interview. After this point the information you have given will have been processed and won't be able to be distinguished from those given by other individuals.

- Just to reassure you-as stated in the information sheet and consent form none of the answers or information that you give will be identifiable to you. The interview will be coded as opposed to being stored against your name. Once the data and information from the interview has been used, the recordings will be wiped from the recording device.

Are there any questions before we start?

\section{Main Body of Questions}

First, I'm keen to try and gain a bit of information about your past experiences of neck pain. Thinking back to the last time you had issues with you neck, what sort of problems or physical symptoms did you experience?

- Are there any further problems/symptoms that you can think of? (pain at rest, pain during or after flying, stiffness, decreased range of motion, headaches, thoracic pain/stiffness).

When you get issues with your neck, what aspects of your daily life does it tend to affect or interfere with?

- Can you tell me a bit more about how your neck pain affects you at work

Flying performance, concentration when flying, desk based work/ flight planning/concentration.

Would you be able to give the pain you typically experience (when flying, when forming combat manoeuvres/when flight planning) a score out of 10 ?

How about social activities and sport?

Military fitness test/running/weight lifting?

Would you be able to give the pain you typically experience a score out of 10 ?

Does your neck pain impact on home life at all?

Sleep and subsequent feeling of fatigue?

Does it ever affect you when driving?

Would you be able to give the pain you typically experience a score out of 10 ?

- Is there anything it stops you doing/activities you have to avoid?

When you get neck pain, are there any thoughts, feeling or concerns that you experience associated with it?

- Does it worry you at all?

\section{Box 1 Continued}

Do you know what it is specifically that worries you? (long-term career implications, fear of ongoing pain/symptoms, affect on family life).

Does it ever make you feel angry or frustrated?

Equipment concerns/budget and funding restrictions.

\section{Conclusions}

Is there anything else that you feel is important that we haven't talked about?

At the beginning of each interview, the participant information sheet was discussed and questions were answered. Confidentiality and the concept of voluntary participation was explained, including the process of withdrawal. All subjects provided written informed consent before participating.

\section{Patient and public involvement}

The study design and methods were informed by our experience of working with practitioners and military aircrew and more specifically fast jet pilots. They actively contributed to the research question and to establish the need for this research. Findings of the study will be shared with key stakeholders.

\section{Data analysis}

Data were analysed according to a recommended process of coding and data analysis, ${ }^{6}$ combined with guidance on thematic analysis. ${ }^{24}$ An initial coding framework was created from the topic guide, hypothesised conceptual framework and data from pilot testing. ${ }^{6}$ The lead researcher (AD) listened to, scored and assigned codes to themes that featured in interview transcripts and documented all modifications to the initial framework, which was expanded and restructured continuously as new data emerged. ${ }^{6}$ A saturation table compiled during data analysis revealed that concept saturation was reached (table 1). Once all transcripts had been processed, a coding dictionary was developed detailing all participant quotes according to each code. This enabled comparison of grouped data and an initial check of coding consistency. ${ }^{24}$ Inductive analysis informed further modifications in coding terminology and theme allocation, ensuring the coding framework and dictionary were a true reflection of participant data and not imposed by previous knowledge. ${ }^{6}$

Coinvestigators (NRH and ES) assisted with data analysis and interpretation to enhance the credibility of study findings. ES, a highly experienced musculoskeletal physiotherapist and researcher, checked coding and theme allocation by matching patient quotes to themes and codes in accordance with previous guidance. ${ }^{25}$ Consensus was achieved regarding theme and subtheme coding. Reflexivity was used throughout and a revised conceptual framework (figure 2B), or thematic map generated for further analysis and interpretation by the research team. ${ }^{624}$ 


\section{Concept}

Endpoints

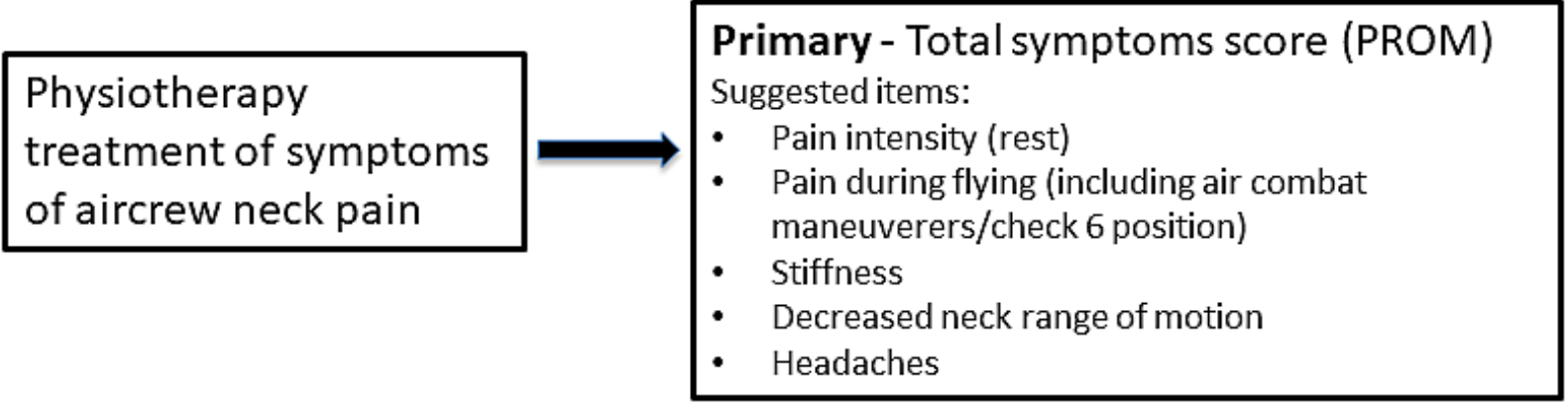

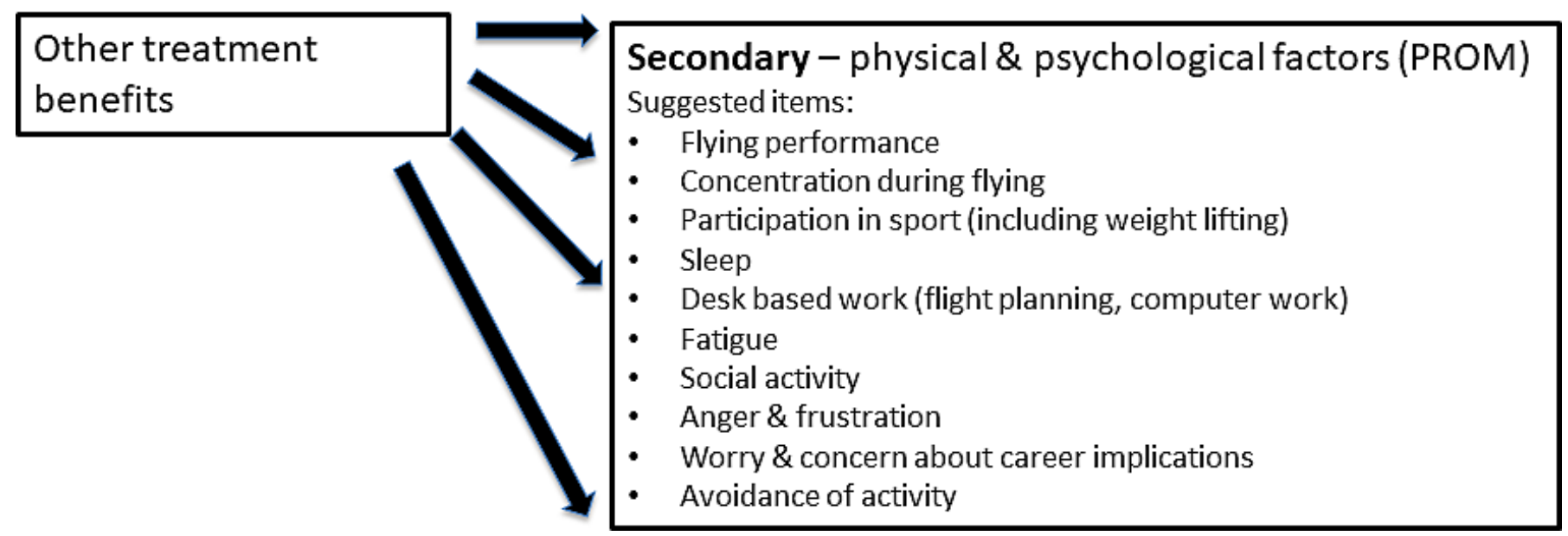

Figure 1 Proposed endpoint model for a new neck specific PROM for military aircrew. PROM, patient-reported outcome measure.

\section{RESULTS}

The sample comprised 10 male RAF fast jet pilots, with mean age 34.7 years (range 29-41 years), and a wide range of flying experience (median 1850 hours, range 650-3000 hours), fast jet flying hours (median 1200 hours, range 300-2400 hours) and incidence of neck pain during their military flying career (median 3.5, range 1-100 incidents).

Findings support significant modifications to the hypothesised conceptual framework (figure 2A) when compared with the revised conceptual framework that was developed following data collection. (figure 2B).

Figure 3A-D illustrates these according to our four derived themes (1) physical symptoms, (2) work-related effects, (3) psychological and emotional effects and (4) social and activity-related effects. Collectively, this includes 13 new subthemes, with 7 modified (work related, flying, physical symptoms, neck pain, social and activity related, psychological and emotional, and worry) and 4 discarded (decreased neck range of motion, desk-based work, fatigue and activity avoidance) as no data were collected to support their inclusion. Only four themes remain unchanged across the two frameworks (headaches, pain at rest, neck stiffness and sleep).
Each theme and subtheme are presented with codes in the form of quotes labelled according to participant (P) number in table 2 .

\section{Theme A: physical symptoms}

When compared with the hypothesised framework, six new subthemes emerged within this theme; with five pain related (when moving, when flying, not wanting to move, after flying and at rest), with pain when flying further subgrouped to include air combat and use of night-vision goggles (NVG). 'Headaches' and 'pain at rest' are the only consistent subthemes across the two frameworks.

Most participants had experienced pain when moving their head and neck, with rotation the most provocative movement. Pain was associated with air combat flying where head position and the application of gravitational force during flying manoeuvres were contributing factors. Some reported pain with NVG flying, especially 'long duration use' or 'long sorties'. Difficulty sustaining the required head position against gravitational force resistance was reported with the neck being 'close to the limit of its strength' and sometimes associated with pain. 


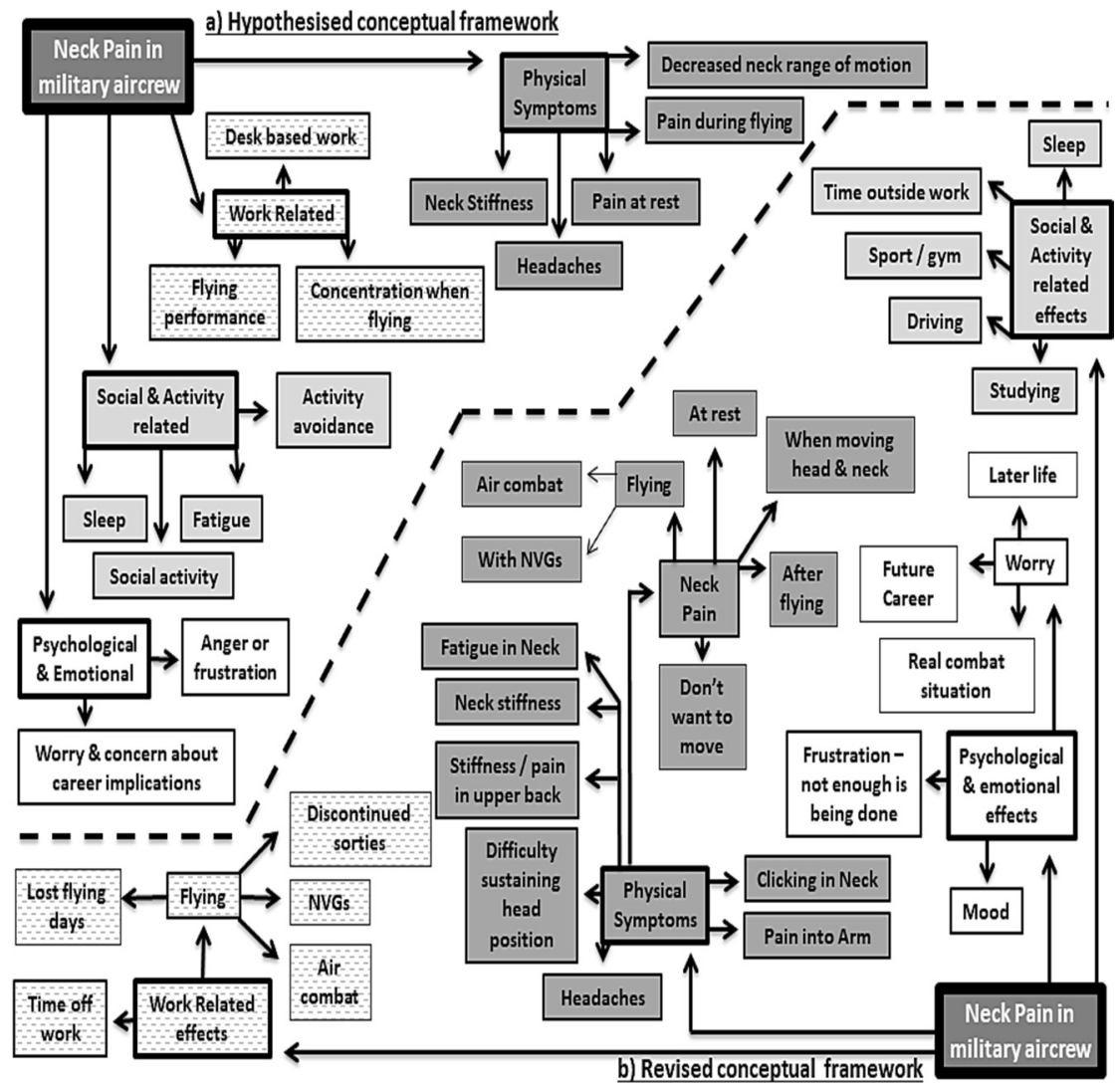

Figure 2 (A) Hypothesised conceptual framework for a neck specific PROM for military aircrew (top left). (B) Revised conceptual framework for a neck specific PROM for military aircrew (bottom right). Thirteen new subthemes were included in the revised conceptual framework, with seven modified (work related, flying, physical symptoms, neck pain, social and activity related, psychological and emotional, and worry) and four discarded (decreased neck range of motion, desk-based work, fatigue and activity avoidance). PROM, patient-reported outcome measure.

Pain duration varied from 'a couple of days' to 'a week and a half' with participants describing delayed onset of pain to one or 2 days postflying; a comparison made with that experienced with delayed-onset muscle soreness or fatigue. 'Fatigue' or 'tiredness' in the neck was widely reported, with contributing factors being long duration sorties, weight of the helmet and NVGs, poor neck positioning and acceleration/gravitational force. Some participants described 'neck stiffness' and used the term interchangeably with reduced neck movement. The term 'decreased neck range of motion' did not reflect the language used by participants and was therefore discarded (figure 2B).

Some described thoracic spine symptoms, describing both tightness and pain in the 'upper back' or 'between the shoulder blades'. Further descriptions included 'pain in the back of my head', and it 'sort of feels like the same muscle' (P2) as the neck were also used, therefore 'headaches' was retained as a subtheme in the revised conceptual framework (figure 2B). Radiating arm symptoms associated with previous acute neck pain episodes, and neck clicking leading to an acute onset of pain were also described. Pain-related fear avoidance was raised and associated with previous acute pain episodes. Some participants described previous episodes of constant symptoms that were present at rest (table 1).

\section{Theme B: work-related effects}

Factors in this theme were modified significantly from the hypothesised framework, with 'flying performance' subdivided to include four subthemes and retention of 'time off work'. Both 'concentration' and 'desk-based work' were removed as no data were yielded to support inclusion.

Many participants admitted limiting their air combat flying to avoid neck pain/injury, specifically restricting manoeuvres and gravitational force, or avoiding certain head positions. Some participants discussed how NVG use was affected, 'flipping them up' or removing them to avoid neck pain. Some participants referred to occasions when they stopped flying early due to neck pain, or were unable to fly or took time off work. The secondary effects and impact on operational output was expanded on by some of the senior aircrew (table 1).

Subthemes within this theme were modified from the hypothesised framework, with 'worry' being divided into three subcategories, and 'anger or frustration' revised to 'frustration'. 'Mood' was included as a new subtheme.

Concern about the quality of life implications of ongoing neck and back problems were raised by some participants. Others expressed worry about neck pain affecting their flying career, with both short-term and long-term concerns reflected. Some pointed to concerns 


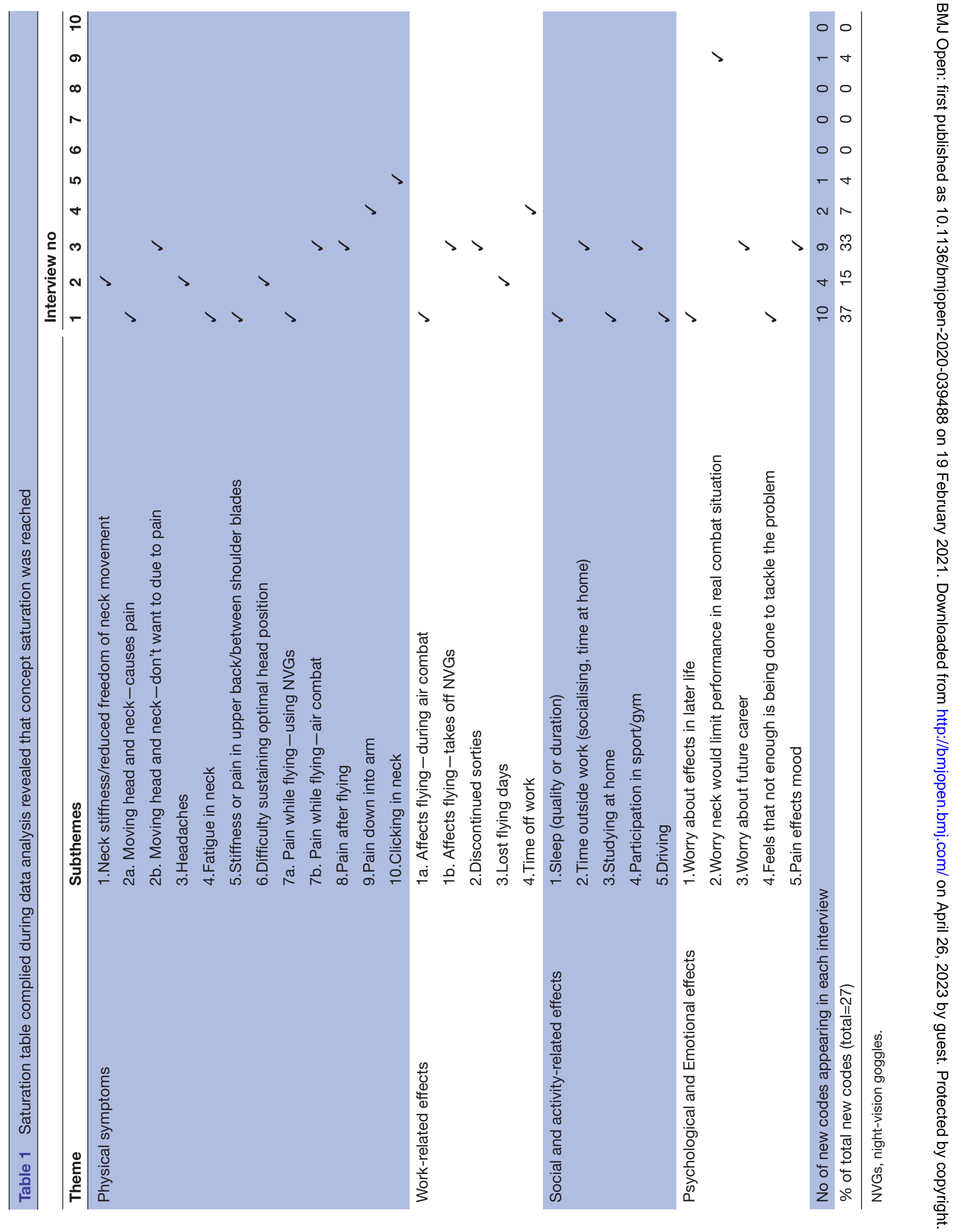




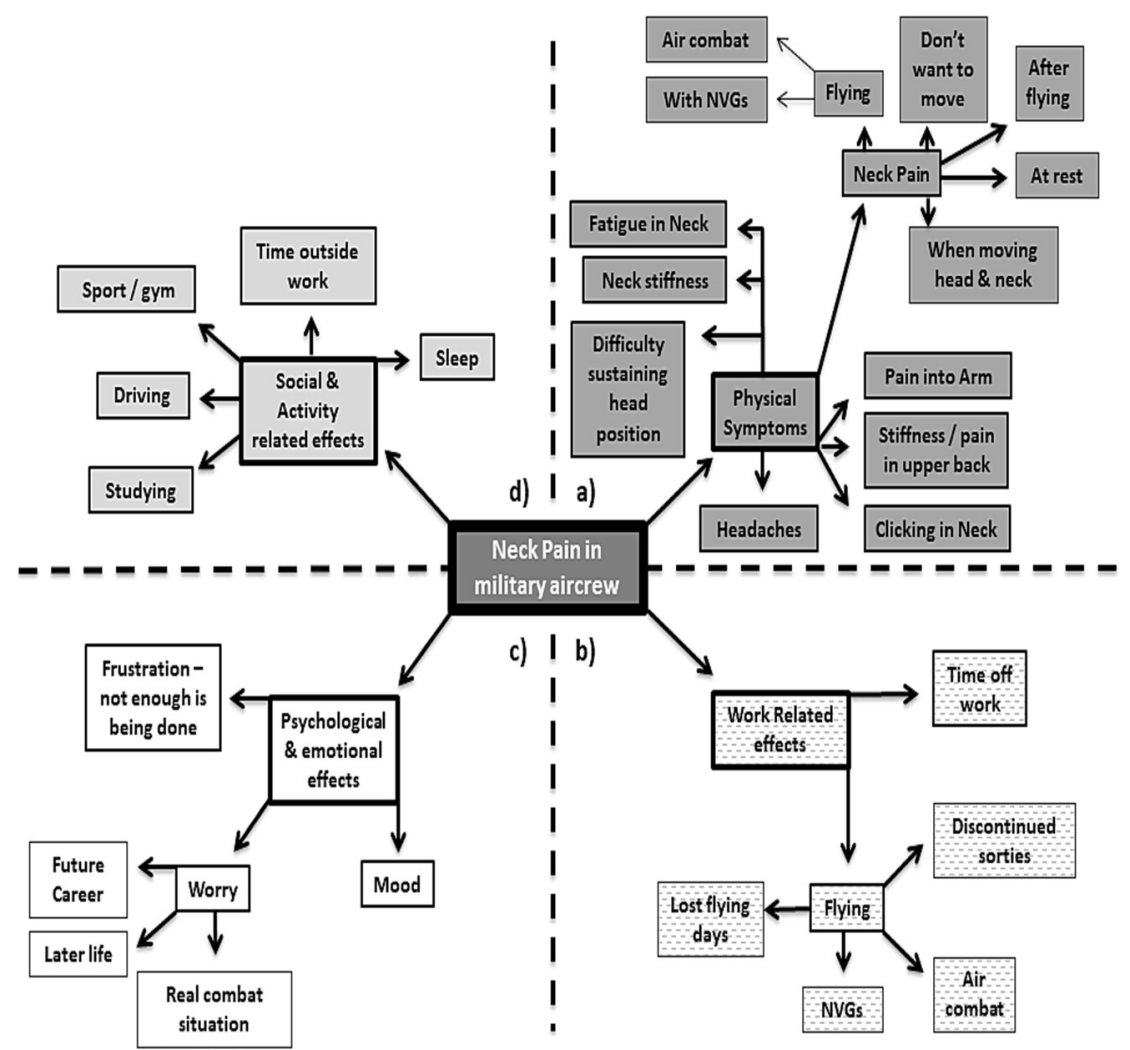

Figure 3 Revised conceptual framework for a neck specific PROM for military aircrew. PROM, patient-reported outcome measure. NVG, night-vision goggles

that neck pain would pose a risk in a real time combat situation. Participants also expressed frustrations that not enough is being done to tackle the issue of neck pain in aircrew with neck symptoms reportedly having an adverse effect mood (table 1).

Three new categories were added to this theme (sport/ gym, driving and studying), while 'fatigue' was removed and 'sleep' remained unchanged. 'Social activity' and 'activity avoidance' were encompassed in 'time outside work'.

Neck pain impacting sleep duration and quality was discussed. The impact of neck pain on time outside work was mentioned, with consequential avoidance of home or social activity. Limiting or stopping sport or weight training was discussed during an acute neck pain episode. Other activities which were impacted by neck pain included driving and home computer use (table 1).

\section{DISCUSSION}

This is the first qualitative study of military aircrew that used in-depth semistructured interviews to investigate flying-related neck pain in fast jet pilots. The study was designed to inform the design and content validity of a pilot specific PROM, focusing on their experiences of occupation related neck pain rather than any current neck pain. ${ }^{23}$ Previous studies involving fast jet pilots used self-administered questionnaires with content analysis and quantitative data processing methods, where prior theory and the researcher's perspective are used to interpret concepts. ${ }^{41526}$ This study used participants words and phrases in 'ground up' concept generation, ensuring data accurately reflects participants perspective, ${ }^{23}$ whereas previous work has examined pilot's neck pain experience, with a focus on physical symptoms. ${ }^{415} 26$ This study additionally examined occupational, psychological and social effects to reflect the wider impact of neck pain on health and function.

\section{Physical symptoms}

Most emergent physical symptoms related to pilot's experience of neck pain, with some expanding on the circumstances of pain onset. Consistent with a recent literature review, ${ }^{27}$ the 'check six' position during air combat flying was cited as a cause of neck pain or injury. This requires pilots to adopt combined end range neck extension, lateral flexion and rotation under $\mathrm{Gz}$, placing considerable biomechanical strain on musculoskeletal tissues and structures. ${ }^{28}$ NVG use adds to head mounted load particularly when worn for prolonged periods, thereby increasing this strain. ${ }^{28}$ Our findings also mirror previous studies where NVG use was linked to in-flight neck pain. ${ }^{12} 14$

Postflight pain onset was also reported which is consistent with a previous fast jet survey. ${ }^{15}$ Participants also discussed pain related fear of movement, as previously found in an experimental study of rotary pilots. ${ }^{13}$ Fear avoidance is thought to provide a protective mechanism against further injury or pain amplification in the acute injury phase. ${ }^{29}$ However, persistent maladaptive behaviours may cause functional activity restriction, ${ }^{30}$ 







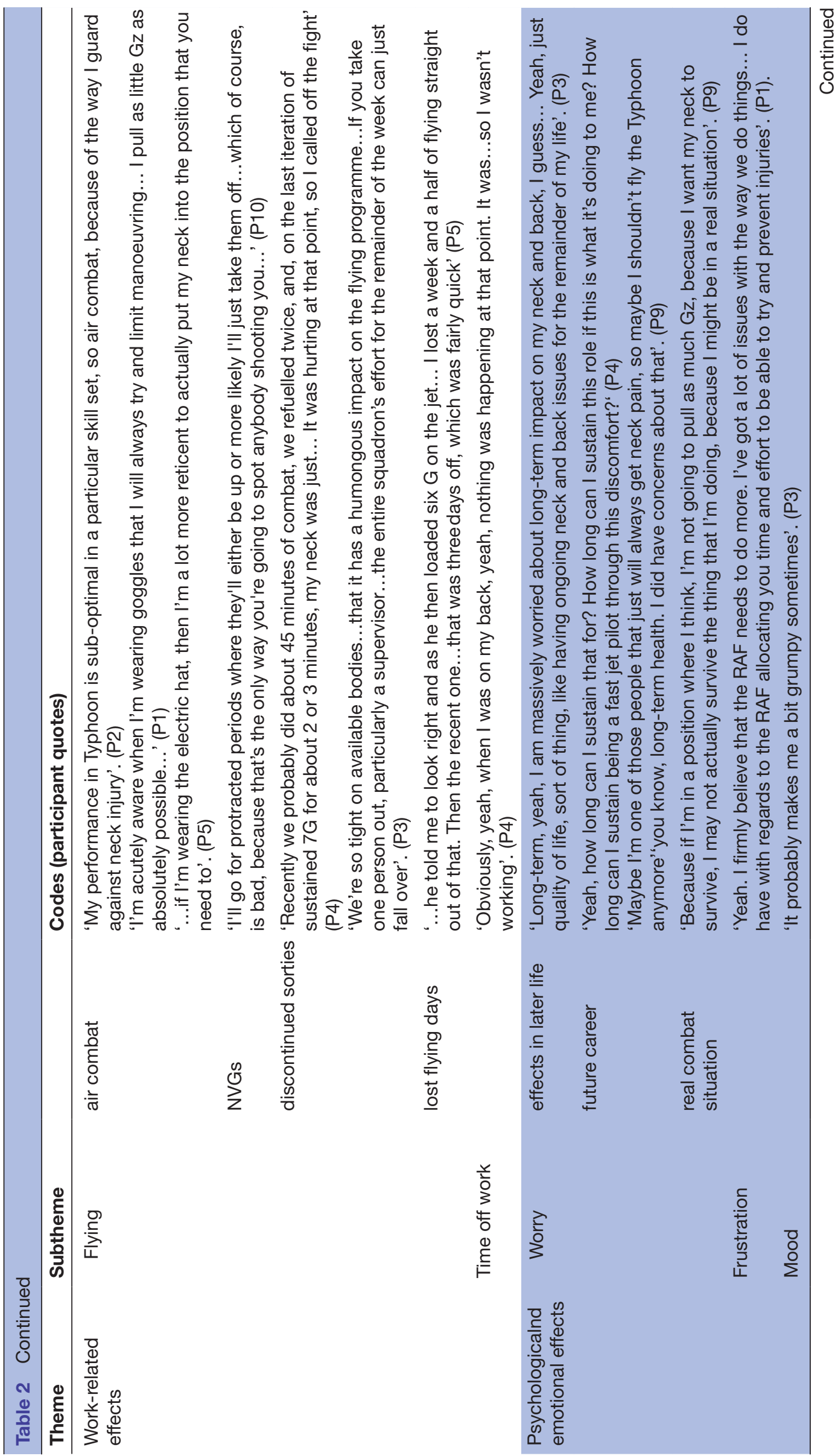


changes in muscle performance $e^{29}$ and transition to chronic or persistent spinal pain.

Neck fatigue was widely reported in this study, but no previous studies having recognised this as a symptom or differentiated this from neck pain. Previous authors have examined neck neuromuscular fatigue as possible injury risk factor, and compared cumulative effects of low with high gravitational force exposures in fast jet aircrew. ${ }^{14}$ In addition, symptoms distal to the neck were reported in this study, with radicular arm symptoms associated with an acute neck pain which is consistent with a previous fast jet survey. ${ }^{15}$ Symptoms of stiffness and pain in the upper back were also reported, although not reflected in any previous military aircrew literature. While previously neck pain was widely considered in isolation interest in the relationship (neurophysiological and biomechanical) between the cervical and thoracic regions has gained momentum. ${ }^{32-34}$ These findings reflect the strength of the concept elicitation interview format that was used in this study, designed to capture patient's perceptions of their condition to inform content validity and PROM development. ${ }^{6}$

\section{Work-related effects}

Most work-related effects involved limitation or modification of flying. Days lost from flying or discontinuation of sorties due to neck pain was both reported and is in keeping with a previous fast jet survey that suggested $42 \%$ of pilots had been temporarily unfit to fly in their career. ${ }^{4}$ Secondary impacts of lost flying time were also revealed, with senior pilots discussing implications for achieving key performance indicators. Participants also described modifications of flying technique due to neck pain, again these impacts are previously unreported. NVG removal to relieve neck pain was widely reported, with pilots acknowledging that this poses a significant flight safety risk. Similarly, participants discussed adapting their methods of flying combat manoeuvres, some raising concerns that reduced flying performance could prove fatal in a realtime scenario.

\section{Psychological and emotional effects}

Worrying due to neck pain was discussed by participants, specifically mentioning impact on future career, later life and performance in a real combat scenario. Effects on mood, with being 'grumpy' raised by one pilot with a history of recurrent neck pain, is encompassed by items on three of six most common neck related PROM. ${ }^{10}$ Responses were similar to that of the Copenhagen Neck Functional Disability Scale (CNFDS) item 'disruption of future'. The interdependence of psychological and emotional functioning and general well-being is well recognised ${ }^{35}$ particularly as the NDI does not represent these domains. ${ }^{36}$ Findings demonstrate the significance of these dimensions to neck pain complaints in military aircrew, and therefore should be reflected in a new population specific PROM. 


\section{Social and activity-related effects}

The social and activity related problems discussed by the participants largely reflect items found in six common neck-related PROM featured in recent literature review ${ }^{10}$ (online supplemental file 2). Sleep and driving were both cited; these feature in four and three of these questionnaires, respectively. ${ }^{10}$ Limitations of sport or gym activities was reported in relation to acute pain, which is a population relevant aspect of the 'recreational activities' item included in four PROM. ${ }^{10}$ Impact on time outside work was discussed which relates to items on the CNFDS, including family relationships and going out with others. ${ }^{37}$

\section{Strengths and limitations}

Several factors may have influenced data collection, analysis and interpretation and affected the trustworthiness of findings. The sample consisted of only males as no female pilots were available at the time of data collection. Despite meeting qualitative interviewing competencies, ${ }^{6}$ the primary researcher $(\mathrm{AD})$ was a relative novice as a qualitative interviewer. Concept saturation was reached in this study but this was assessed retrospectively, whereas assessment throughout data collection is recommended and would have improved methodology. ${ }^{6}$ Data coding was conducted by the primary researcher (AD) and cross checked by another researcher (ES) after completion. While time constraints limited the extent of member checking and transcript validation inductive analysis ensured the coding framework and dictionary were a true reflection of participant data. ${ }^{6}$

\section{Implications for practice and future research}

Findings can be used to inform the current practice of physiotherapists working with military aircrew with neck pain. In the absence of a population-specific measure, clinicians should ensure biopsychosocial impact factors of flying are assessed during the patient history taking. Further qualitative research is required to build on these findings and develop a population-specific PROM; cognitive interviewing would test the range and interpretation of concepts and refine the new PROM items. ${ }^{38}$ Once a PROM has been developed and validated for fast jet aircrew, it would require revalidation in other military aircrew groups. A population-specific measure would enable investigation of the effectiveness of the ACP, and daily physiotherapy practice to mitigate against neck pain in this unique population.

\section{CONCLUSION}

Flight-related neck pain has a broad impact on the lives of fast jet pilots, including physical symptoms, occupational, psychological and social effects. Physical symptoms were largely associated with neck pain, but other clinically relevant factors included symptoms in other body regions and fear avoidance patterns. Occupational factors included modifications and restrictions of flying, some of which may have flight safety implications. Psychological effects expanded on feelings of worry, including impact on future quality of life. Social and activity factors reflected items in existing PROM. Further qualitative research is required to develop and validate a population specific PROM for military aircrew.

Twitter Ellen Slungaard @eslungaard and Nicola R Heneghan @HeneghanNicola

Acknowledgements The authors would like to thank the RAF Typhoon Pilots who were generous with their time and openly discussed their thoughts and experiences. Many thanks to the Musculoskeletal Association of Chartered Physiotherapists, and the Ministry of Defence Academic Deanery, who both provided funds towards this study.

Contributors $A D$ and NRH conceived the idea for the study. $A D$ conducted the interviews with $\mathrm{ES}$ cross-checking them. $\mathrm{AD}$ and $\mathrm{NRH}$ analysed the data. $\mathrm{AD}$ and NRH wrote the first draft. All authors reviewed and provided additional review comments. All authors provided their full approval prior to submission.

Funding The Musculoskeletal Association of Chartered Physiotherapists, and the Ministry of Defence Academic Deanery both provided funds towards this study.

Competing interests None declared.

Patient consent for publication Not required.

Ethics approval The study protocol was approved in advance by the Ministry of Defence Research Ethics Committee (reference 844/MODREQ/18, 29 June 2018), and the University of Birmingham Ethics Committee.

Provenance and peer review Not commissioned; externally peer reviewed.

Data availability statement De-identified participant data may be available from the corresponding author on reasonable request n.heneghan@bham.ac.uk.

Supplemental material This content has been supplied by the author(s). It has not been vetted by BMJ Publishing Group Limited (BMJ) and may not have been peer-reviewed. Any opinions or recommendations discussed are solely those of the author(s) and are not endorsed by BMJ. BMJ disclaims all liability and responsibility arising from any reliance placed on the content. Where the content includes any translated material, BMJ does not warrant the accuracy and reliability of the translations (including but not limited to local regulations, clinical guidelines, terminology, drug names and drug dosages), and is not responsible for any error and/or omissions arising from translation and adaptation or otherwise.

Open access This is an open access article distributed in accordance with the Creative Commons Attribution Non Commercial (CC BY-NC 4.0) license, which permits others to distribute, remix, adapt, build upon this work non-commercially, and license their derivative works on different terms, provided the original work is properly cited, appropriate credit is given, any changes made indicated, and the use is non-commercial. See: http://creativecommons.org/licenses/by-nc/4.0/.

\section{ORCID iDs}

Ellen Slungaard http://orcid.org/0000-0002-7544-8876

Nicola R Heneghan http://orcid.org/0000-0001-7599-3674

\section{REFERENCES}

1 Wickes SJ, Greeves JP. Prevalence and associated factors of flight-related neck pain. Farnborough (UK), in tech report No. 01069 QinetiQ, editor 2006.

2 Murray M, Lange B, Chreiteh SS, et al. Neck and shoulder muscle activity and posture among helicopter pilots and crewmembers during military helicopter flight. J Electromyogr Kinesiol 2016;27:10-17.

3 Cohen SP. Epidemiology, diagnosis, and treatment of neck pain. Mayo Clin Proc 2015;90:284-99.

4 Netto K, Hampson G, Oppermann B, et al. Management of neck pain in Royal Australian air force fast jet aircrew. Mil Med 2011;176:106-9.

5 Slungaard E, Pollock RD, Stevenson AT, et al. Aircrew conditioning programme impact on $+\mathrm{Gz}$ tolerance. Aerosp Med Hum Perform 2019;90:764-73.

6 Patrick DL, Burke LB, Gwaltney CJ, et al. Content validity-establishing and reporting the evidence in newly developed patient-reported outcomes (PRO) instruments for medical product evaluation: ISPOR PRO good research practices task force report: part 1--eliciting concepts for a new PRO instrument. Value Health 2011a;14:967-77. 
7 Coppack RJ, Ladlow P, Bennett AN. Developing UK defence rehabilitation research priorities: a 2020 clinical practitioner engagement exercise. BMJ Mil Health,

8 Kyte DG, Calvert M, van der Wees PJ, et al. An introduction to patient-reported outcome measures (PROMs) in physiotherapy. Physiotherapy 2015;101:119-25.

9 Boyce MB, Browne JP. Does providing feedback on patientreported outcomes to healthcare professionals result in better outcomes for patients? A systematic review. Qual Life Res 2013;22:2265-78

10 Terwee CB, Schellingerhout JM, Verhagen AP, et al. Methodological quality of studies on the measurement properties of neck pain and disability questionnaires: a systematic review. J Manipulative Physiol Ther 2011;34:261-72.

11 Mokkink LB, Terwee CB, Patrick DL, et al. The COSMIN checklist for assessing the methodological quality of studies on measurement properties of health status measurement instruments: an international Delphi study. Qual Life Res 2010;19:539-49.

12 Ang B, Harms-Ringdahl K. Neck pain and related disability in helicopter pilots: a survey of prevalence and risk factors. Aviat Space Environ Med 2006;77:713-9.

13 Ang BO. Impaired neck motor function and pronounced pain-related fear in helicopter pilots with neck pain - a clinical approach. $J$ Electromyogr Kinesiol 2008;18:538-49.

14 Harrison MF, Neary JP, Albert WJ, et al. Measuring neuromuscular fatigue in cervical spinal musculature of military helicopter aircrew. Mil Med 2009;174:1183-9.

15 Jones JA, Hart SF, Baskin DS, et al. Human and behavioral factors contributing to spine-based neurological cockpit injuries in pilots of high-performance aircraft: recommendations for management and prevention. Mil Med 2000;165:6-12.

16 Beaton DE, Bombardier C, Guillemin F, et al. Guidelines for the process of cross-cultural adaptation of self-report measures. Spine 2000;25:3186-91.

17 Riches A, Spratford W, Witchalls J, et al. A systematic review and meta-analysis about the prevalence of neck pain in fast jet pilots. Aerosp Med Hum Perform 2019;90:882-90.

18 Hoving JL, O'Leary EF, Niere KR, et al. Validity of the neck disability index, Northwick Park neck pain questionnaire, and problem elicitation technique for measuring disability associated with whiplash-associated disorders. Pain 2003;102:273-81.

19 Pinfold M, Niere KR, O'Leary EF, et al. Validity and interna consistency of a whiplash-specific disability measure. Spine 2004;29:263-8.

20 Tong A, Sainsbury P, Craig J. Consolidated criteria for reporting qualitative research (COREQ): a 32-item checklist for interviews and focus groups. Int J Qual Health Care 2007;19:349-57.

21 Guzman J, Hurwitz EL, Carroll LJ, et al. A new conceptual model of neck pain: linking onset, course, and care: the bone and joint decade 2000-2010 Task force on neck pain and its associated disorders. Spine 2008;33:S14-23.
22 Green BN, Dunn AS, Pearce SM, et al. Conservative management of uncomplicated mechanical neck pain in a military aviator. $J$ Can Chiropr Assoc 2010;54:92-9.

23 Lasch KE, Marquis P, Vigneux M, et al. Pro development: rigorous qualitative research as the crucial Foundation. Qual Life Res 2010;19:1087-96.

24 Braun V, Clarke V. Using thematic analysis in psychology. Qual Res Psychol 2006;3:77-101.

25 Thomas DR. A general inductive approach for analyzing qualitative evaluation data. Am J Eval 2006;27:237-46.

26 Tucker B, Netto K, Hampson G, et al. Predicting neck pain in Royal Australian air force fighter pilots. Mil Med 2012;177:444-50.

27 Shiri R, Frilander H, Sainio M, et al. Cervical and lumbar pain and radiological degeneration among fighter pilots: a systematic review and meta-analysis. Occup Environ Med 2015;72: :145-50.

28 Coakwell MR, Bloswick DS, Moser R. High-Risk head and neck movements at high $\mathrm{G}$ and interventions to reduce associated neck injury. Aviat Space Environ Med 2004;75: :68-80.

29 Vlaeyen JWS, Seelen HAM, Peters M, et al. Fear of movement/(re) injury and muscular reactivity in chronic low back pain patients: an experimental investigation. Pain 1999;82:297-304.

30 Crombez G, Vlaeyen JW, Heuts PH, et al. Pain-Related fear is more disabling than pain itself: evidence on the role of pain-related fear in chronic back pain disability. Pain 1999;80:329-39.

31 Nederhand MJ, Hermens HJ, ljzerman MJ, et al. The effect of fear of movement on muscle activation in posttraumatic neck pain disability. Clin J Pain 2006;22:519-25.

32 Heneghan NR, Rushton A. Understanding why the thoracic region is the 'Cinderella' region of the spine. Man Ther 2016;21:274-6.

33 Heneghan NR, Smith R, Tyros I, et al. Thoracic dysfunction in whiplash associated disorders: a systematic review. PLoS One 2018;13:e0194235.

34 Tsang SMH, Szeto GPY, Lee RYW. Normal kinematics of the neck: the interplay between the cervical and thoracic spines. Man Ther 2013;18:431-7.

35 Wallis BJ, Lord SM, Barnsley L, et al. Pain and psychologic symptoms of Australian patients with whiplash. Spine 1996;21:804-10.

36 van Randeraad-van der Zee $\mathrm{CH}$, Beurskens AJHM, Swinkels RAHM, et al. The burden of neck pain: its meaning for persons with neck pain and healthcare providers, explored by concept mapping. Qual Life Res 2016;25:1219-25.

37 Badaró FAR, Araújo RC, Behlau M. The Copenhagen neck functional disability scale - CNFDS: translation and cultural adaptation to Brazilian Portuguese. J Hum Growth Dev 2014;24:304-13.

38 Patrick DL, Burke LB, Gwaltney CJ, et al. Content validity-establishing and reporting the evidence in newly developed patient-reported outcomes (PRO) instruments for medical product evaluation: ISPOR PRO Good Research Practices Task Force report: part 2--assessing respondent understanding. Value Health 2011b;14:978-88. 